\section{Corticosteroid-induced osteoporosis in patients with uveitis}

NP Jones ${ }^{1}$, LC Anderton ${ }^{1}$, FM Cheong ${ }^{2}$, A Whallett $^{3}$, MR Stanford ${ }^{2}$, PI Murray ${ }^{3}$, S Lesnik-Oberstein ${ }^{4}$ and C Pavesio ${ }^{4}$

\begin{abstract}
Aims To estimate the prevalence of low bone density and osteoporosis in a population of patients with uveitis taking systemic steroid treatment; to clarify the risks of steroid-induced fracture and to suggest a protocol for the prevention and management of bone loss in patients with ophthalmic inflammatory disease.
\end{abstract}

Methods Bone densitometry was performed on 129 adult patients with prednisolonetreated uveitis from four centres. Information on uveitis diagnosis, associated risk factors, steroid dosage and treatment duration, prophylaxis and management, was collected. Juveniles, patients with scleritis and those who had used deflazacort, were excluded. Results Steroid treatment time varied from 13 weeks to 31 years, and the total dosage from $1.29 \mathrm{~g}$ to $166.5 \mathrm{~g}$. Twenty-six percent of patients also used one or more immunosuppressives. Forty-eight percent had additional risk factors for bone loss. Bone density was abnormally low in $44.2 \%$, and $\mathbf{1 5 . 5 \%}$ had osteoporosis. Osteoporosis was substantially more common in males $(20.6 \%$, all under $60 \mathrm{yrs})$ than in females $(9.8 \%)$. Seven symptomatic fractures occurred in patients on treatment. Bone loss correlated with total steroid dose, mean dose, duration of treatment and the presence of pre-existing risk factors.

Conclusions The prevalence of steroidinduced osteoporosis and fracture is low for patients with uveitis but young males are at risk. Patients at high risk should be identified, and prophylaxis and treatment should be used as required. The guideline of the National Osteoporosis Society is recommended as a management protocol. Eye (2002) 16, 587-593. doi:10.1038/ sj.eye. 6700163

Keywords: uveitis; ocular inflammatory disease; corticosteroids; bone densitometry; osteopenia; osteoporosis; fracture

\section{Introduction}

Osteoporosis is a reduction in bone density which increases its fragility and therefore the risk of fracture. Bone density can be quantified by a variety of methods, and is usually expressed either as a variation from a sex and age-matched mean (Z-score) or from an optimal, sex-matched young adult mean (T-score). If the bone density is worse than one standard deviation below an optimal mean (T-score $<-1.0$ ), the term osteopenia is used; if the T-score is $<-2.5$, the patient has osteoporosis. If an osteoporotic person has already suffered a fracture, the term established osteoporosis is used. Osteoporosis may be primary (age- and/or sex-related) or secondary to a variety of other factors; the most common of these is systemic steroid therapy.

Ophthalmologists use systemic steroid treatment regularly, to treat intraocular and orbital inflammatory disease, scleritis, optic neuritis and thyroid eye disease. A 1997 survey of consultant ophthalmologists ${ }^{1}$ showed that three quarters prescribed steroids in significant doses but that only $25 \%$ of these gave advice to patients on the prevention of osteoporosis. A 1999 study in general practice ${ }^{2}$ showed that only $14 \%$ of steroid users were prescribed prophylactic treatment against bone loss. Although the literature on steroidinduced osteoporosis is now extensive, it has been largely confined to the rheumatological and specialist medical literature. Two informative papers on the side-effects of steroids have been produced, by Stanbury \& Graham $^{3}$ and by Jabs et al, ${ }^{4}$ but information on osteoporosis has not been readily accessible to the ophthalmological community.

Systemic steroid therapy is most frequently used by ophthalmologists to treat uveitis. Although steroid-induced bone loss in some diseases has been well-documented, it is clear that there is an intrinsic risk of osteoporosis in those diseases most studied, including inflammatory arthropathies, asthma and
${ }^{1}$ The Royal Eye Hospital Manchester, UK

${ }^{2}$ St Thomas' Hospital London, UK

${ }^{3}$ Birmingham \& Midland Eye Centre Birmingham, UK

${ }^{4}$ Moorfields Eye Hospital London, UK

Correspondence: NP Jones Consultant Ophthalmic Surgeon Manchester Royal Eye Hospital

Oxford Road

Manchester M13 9WH, UK

Tel: 01612765628

Fax: 01612726618

E-mail: njones@central. cmht.nwest.nhs.uk 
inflammatory bowel disease. It may be unjustified to extrapolate the perceived risks to a population of uveitis patients, particularly those without associated systemic disease. No previous study has examined bone loss in any population of ophthalmic patients. We therefore retrospectively evaluated bone density in steroid-treated patients attending uveitis clinics in order to quantify bone loss in these patients, and suggest an approach to the prevention or minimisation of this potentially serious complication.

\section{Patients and methods}

From an adult population of patients attending the Uveitis Clinics at the Manchester Royal Eye Hospital, St Thomas' Hospital, Birmingham \& Midland Eye Centre and Moorfields Eye Hospital, those using systemic prednisolone for 3 months or longer who had undergone bone densitometry, were identified. Data were retrieved from medical records including age, sex, race and diagnosis.

Bone density was assessed using dual-emission X-ray absorptiometry (DEXA) of lumbar spine and proximal femur (Figure 1). Patients were categorised as normal (T-score -1.0 or better), osteopenia (T-score $-2.5 \leq$ -1.0 ) or osteoporosis (T-score $<-2.5$ ).

Detailed information on steroid usage was noted for

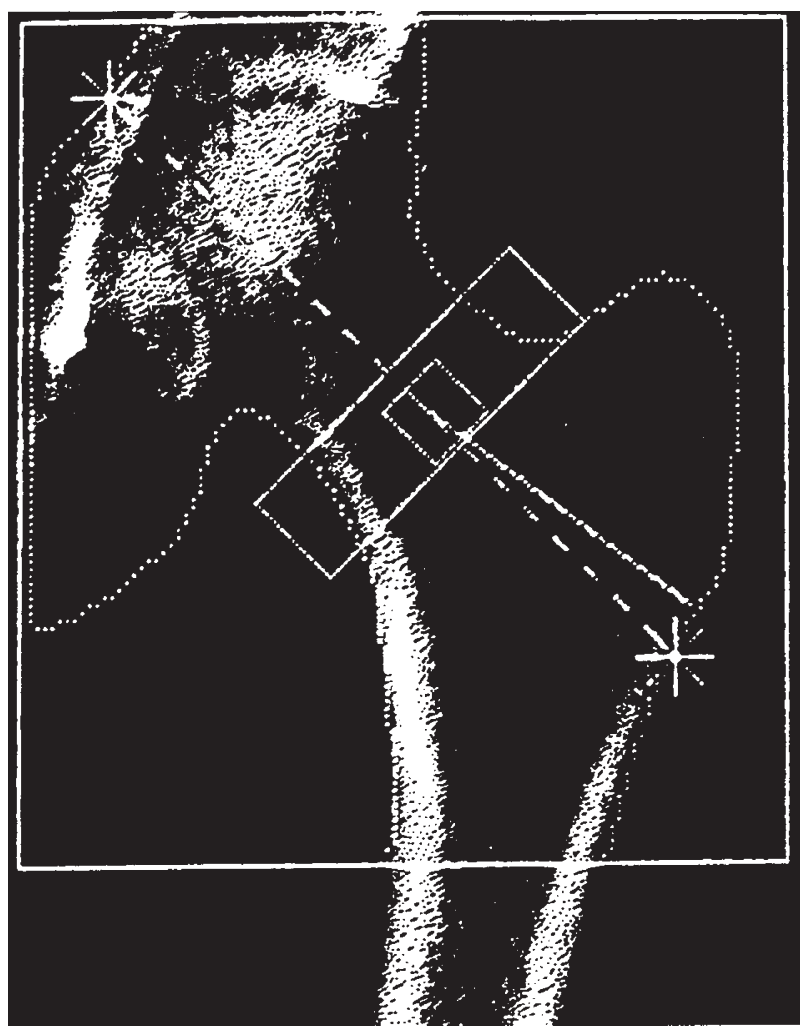

Figure 1 A typical bone densitometry scan of the upper femur. the entire duration of treatment up to the date of DEXA. From these data the total duration of steroid treatment between commencement and DEXA, total dose and mean daily dose were calculated. The coexistence of other risk factors for osteoporosis was noted, as was the use of prophylaxis, if any, against bone loss. Patients were excluded if steroids had been used at any time under the age of 16 years, if data were incomplete, if they had scleritis, or if they had used deflazacort. If intravenous or depot intramuscular methylprednisolone or other immunosuppressive treatment had been used, such events were noted.

\section{Results}

One hundred and twenty-nine patients were included in the study, of whom $68(53 \%)$ were male and 61 $(47 \%)$ female. One hundred and nine $(84.5 \%)$ were Caucasian, six $(4.6 \%)$ black and 14 from other racial groups. The age at densitometry ranged from 19 to 88 , and the age distribution for both sexes is shown in Figure $2 a$ and $b$. The causes of uveitis where known, or the main manifestations of inflammation, are shown in Table 1.

Treatment time varied from 13 weeks to 31 years (mean 3.6 years). The cumulative dose ranged from $1290 \mathrm{mg}$ to $166559 \mathrm{mg}$ (mean $16849 \mathrm{mg}$ ) and the mean dose ranged from $2.8 \mathrm{mg} /$ day to $41 \mathrm{mg}$ / day (mean $13.6 \mathrm{mg}$ /day).

At some time during treatment a total of 34 patients $(26.4 \%)$ also received treatment with

immunosuppressives (up to three drugs) as steroidsparing or preferred medication. The drugs involved are shown in Table 2. In addition, eight patients received intramuscular depot injections and four patients intravenous pulses, of methylprednisolone.

A total of 62 patients ( $48 \%$ ) had one to four potential risk factors for osteoporosis prior to the

commencement of steroid treatment, as shown in Table 3. Seventeen patients $(13.2 \%)$ used prophylaxis against bone loss; 12 with Calcium \pm Vitamin D3; four with hormone replacement therapy (HRT) and one with both of these.

Bone densitometry was within the normal range in 72 patients $(55.8 \%)$ but was low in the remainder, 37 $(28.7 \%)$ having osteopenia and 20 (15.5\%) osteoporosis. Of the 20 osteoporotics, 14 were male and six female. Comparing these two groups, pre-existing risk factors were identified in 6/6 osteoporotic women and 9/14 men; the mean steroid dose was $13.6 \mathrm{mg} /$ day for men, but $18.9 \mathrm{mg} /$ day for women. The total steroid dose was $30.1 \mathrm{~g}$ for men compared to $20.4 \mathrm{~g}$ for women; the mean treatment duration was 6.4 yrs for osteoporotic men, but 4 yrs for women. None of these treatment 
a 68 male patients

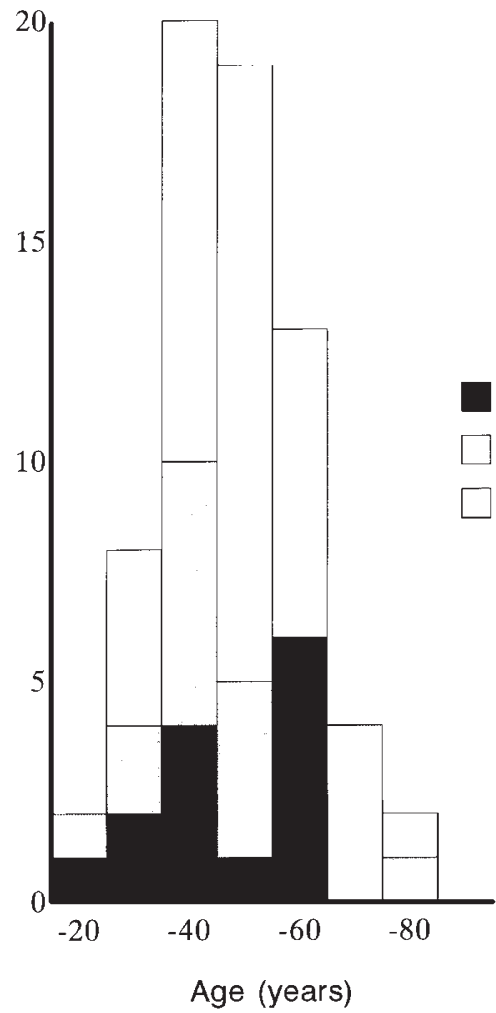

b 61 female patients

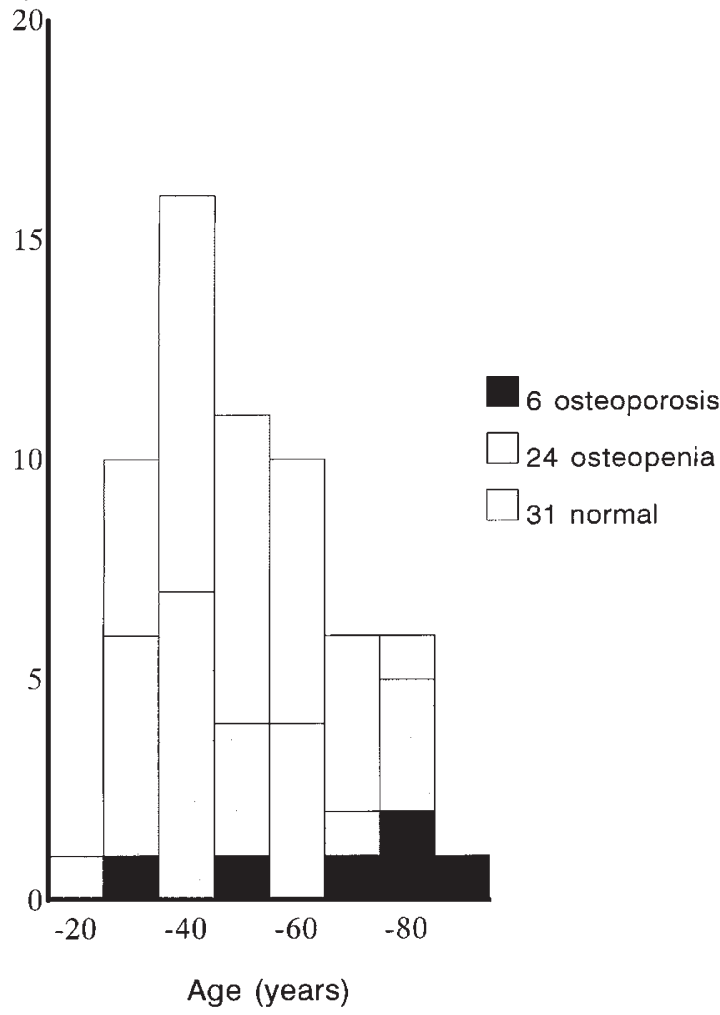

Figure 2 The age distribution for (a) male and (b) female patients in this series, showing the proportion in each age group with normal bone density, osteopenia and osteoporosis.

Table 1 The underlying uveitis diagnosis

\begin{tabular}{lcc}
\hline Diagnosis & Number of patients & \% of sample \\
\hline Idiopathic chronic & 44 & 34.1 \\
posterior/panuveitis & & \\
Behçet's disease & 21 & 16.3 \\
Sarcoidosis & 13 & 10.1 \\
Idiopathic intermediate & 11 & 8.5 \\
uveitis & & \\
Primary retinal vaculitis & 10 & 7.7 \\
Sympathetic uveitis & 9 & 7.0 \\
Arthropathy-associated & 6 & 4.6 \\
Birdshot & 6 & 4.6 \\
retinochoroidopathy & 3 & 2.3 \\
Tuberculosis & 3 & 2.3 \\
Vogt-Koyanagi-Harada & & \\
syndrome & 3 & 2.3 \\
Miscellaneous & 129 & 100 \\
Total & & \\
\hline
\end{tabular}

a Including ankylosing spondylitis, Reiter's syndrome, psoriatic arthropathy.
Table 2 Additional systemic anti-inflammatory and immunosuppressive treatment

\begin{tabular}{lcc}
\hline Treatment & $\begin{array}{c}\text { Number of } \\
\text { patients }\end{array}$ & \% of sample \\
\hline Azathioprine & 13 & 10.1 \\
Colchicine & 1 & 0.7 \\
Cyclophosphamide & 2 & 1.5 \\
Cyclosporin & 27 & 20.9 \\
Methotrexate & 4 & 3.1 \\
Mycophenelate mofetil & 2 & 1.5 \\
Methylprednisolone- & 8 & 6.2 \\
intramuscular & & \\
Methylprednisolone- & 4 & 3.1 \\
intravenous & & \\
\hline
\end{tabular}

parameters were significantly different between males and females.

Overall 57 patients $(44.2 \%)$ had low bone density; in 32 of these cases the maximally-affected site was specified in the densitometry report; in 23 of these the lower spine was most affected, and the hip in nine. Eight symptomatic fractures occurred in seven patients (five men, two women) during steroid treatment; three had normal bone densitometry, one had osteopenia and three had (established) osteoporosis. 
Table 3 Pre-existing risk factors for osteoporosis

\begin{tabular}{lccc}
\hline Risk factor & $\begin{array}{c}\text { Number } \\
\text { of patients }\end{array}$ & $\begin{array}{c}\text { \% of } \\
\text { patients }\end{array}$ & $\begin{array}{c}\% \text { of } \\
\text { women }\end{array}$ \\
\hline $\begin{array}{l}\text { Post-menopausal } \\
\text { woman }\end{array}$ & 18 & & $29.5 \%$ \\
Smoker & 14 & 10.8 & \\
Sarcoidosis & 13 & 10.1 & \\
Inflammatory & 10 & 7.7 & \\
arthropathy & & & \\
Pregnancy & 9 & & \\
Inflammatory & 3 & 2.3 & \\
bowel disease & & & \\
Amenorrhoea/ & 3 & & \\
oophorectomy & & & \\
Diabetes & 3 & $2.3 \%$ \\
Anorexia/vegan diet & 2 & 0.7 & \\
Hyperparathyroidism & 1 & 0.7 & \\
Hypogonadism & 1 & 48 & \\
One or more risk & 62 & & \\
factors & & & \\
\hline
\end{tabular}

\section{Discussion}

Systemic steroid treatment induces bone loss in several ways; doses greater than $10 \mathrm{mg} /$ day inhibit dietary calcium absorption; suppression of androgen production depresses oestrone levels and suppresses the calcitonin response, leading to increased bone reabsorption; osteoclasis is stimulated; and bone formation is reduced. Bone loss is inevitable during steroid therapy and commences within days of starting treatment. The rate of loss is greatest within the first 6 months, during which time typically $4-5 \%$ of bone is lost. ${ }^{5}$ Eventually osteoporosis occurs in up to $50 \%$ of patients. ${ }^{6}$ Trabecular bone is particularly affected, so effects are more marked in the spine (where steroid treatment is responsible for up to $20 \%$ of all crush fractures ${ }^{7}$ ) and proximal femur. Overall, the prevalence of symptomatic or asymptomatic fractures in patients treated with systemic steroids is between 11 and $20 \%{ }^{8}$ this represents a 2.5-3 times increased risk of fracture compared with a control population. ${ }^{9}$

Bone density may be assessed by plain radiography, quantitative computed tomography, ultrasonography or absorptiometry using photons or X-rays. ${ }^{10}$ DEXA scanning is now the most widely available technique in the UK and was used in this study. It is rapid, taking less than 5 min per site, uses little radiation (less than $1 \mu \mathrm{Sv}$ for a spine scan) and is relatively inexpensive. There are problems of reproducibility in any method of bone densitometry, between machines and longitudinally in a single patient. Data should therefore be interpreted within these limitations, and it should be noted that DEXA assessments in this series were made on at least four different machines.
Our study of 129 patients has shown a high incidence of bone loss but a low incidence of fracture. The presence of pre-existing risk factors correlated strongly with bone loss (Table 4). There was also a trend towards higher total steroid dose (normal = $14.8 \mathrm{~g}$, osteoporosis $=27.2 \mathrm{~g}$ ), mean steroid dose (normal $13.6 \mathrm{mg}$, osteoporosis $15.2 \mathrm{mg}$ ) and treatment time (normal $2.8 \mathrm{yrs}$, osteoporosis $5.6 \mathrm{yrs}$ ), in association with bone loss (Table 4). However, none of these parameters reached statistical significance for this sample.

Some diseases have an intrinsic risk of bone loss. Steroid-treated rheumatoid arthritis has a high rate of osteoporosis in comparison to asthma or polymyalgia rheumatica, but these also carry some intrinsic risk. ${ }^{11-13}$ The prevalence of low bone density has not been investigated in patients with ophthalmic inflammatory disease, but one previous study examined 15 patients with steroid-treated thyroid eye disease ${ }^{14}$ and found that four were osteoporotic, and a study of 602 patients with various ocular inflammatory diseases identified 17 pathological fractures (2.8\%). ${ }^{15}$ The selection of patients for our study was neither comprehensive nor prospective and the results cannot reliably be extrapolated to a wider population. However, it is likely that patients included were selected for perceived risk. Because of this sampling bias, it is most unlikely that these 129 patients represented an underestimate of steroid-induced bone loss in uveitis patients. In our cohort the prevalence of osteoporosis was $15 \%$ and the symptomatic fracture rate, $6 \%$. Indeed, only four patients with low bone density suffered a fracture ( $3 \%$ of all patients), which represents one such event per 118 patients treatment years. The reported prevalence of osteoporosis and

Table 4 Steroid dosage, risk factors, fractures and bone loss

\begin{tabular}{lccc}
\hline & \multicolumn{3}{c}{ (DEXA scan result) } \\
\cline { 2 - 4 } & Normal & Osteopenia & Osteoporosis \\
\hline $\begin{array}{l}\text { Patient number } \\
\quad \text { (Males) }\end{array}$ & 72 & 37 & 20 \\
$\quad$ (Females, & 41 & 13 & $14)$ \\
$\quad \begin{array}{l}\text { pre-menopausal) } \\
\quad \text { Females, }\end{array}$ & 24 & 17 & $2)$ \\
$\quad$ post-menopausal) & 7 & 7 & $4)$ \\
$\begin{array}{l}\text { Mean age } \\
\begin{array}{l}\text { Pre-existing risk } \\
\text { factors (\%) }\end{array}\end{array}$ & 45.1 & 42 & 47.8 \\
$\begin{array}{l}\text { Mean steroid dose } \\
\text { (mg/day) }\end{array}$ & 22 & 51 & 75 \\
$\begin{array}{l}\text { Cumulative steroid } \\
\text { dose (g) }\end{array}$ & 13.5 & 12.8 & 15.2 \\
Treatment time (yrs) & 2.8 & 15.2 & 27.2 \\
Fractures on treatment & 4 & 4.0 & 5.6 \\
\hline
\end{tabular}


fracture in other disease groups is substantially higher, including a $34 \%$ rate of vertebral fracture in rheumatoid arthritis treated with $5 \mathrm{mg}$ /day or more of prednisolone over $5 \mathrm{yrs}^{16}$ and a $42 \%$ rate of fracture in asthmatics on high-dose prednisolone. ${ }^{17}$ Uveitis per se shows no evidence of an intrinsic risk of bone loss.

Some patients (indeed, nearly half of our patients) taking systemic steroid treatment had additional risks for osteoporosis and it is important to identify these (Table 3). Eighteen women were post-menopausal and nine had pregnancies during treatment. Three had previous episodes of amenorrhoea or had undergone oophorectomy, both of which are potent causes of osteoporosis. ${ }^{18}$ Smoking (11\% of this cohort) accelerates bone resorption and in women, accelerates the menopause and catabolises oestrogens thereafter. Some patients with sarcoidosis have hypercalcuria and lose bone. Osteoporosis is weakly associated with inflammatory bowel disease, partly because of malabsorption. ${ }^{19}$ Inflammatory arthropathy, particularly rheumatoid arthritis ${ }^{20}$ leads to bone loss, not least because of decreased mobility; total immobilisation leads to bone resorption at a rate of $1 \%$ per week. Type 1 diabetics have on average a $10 \%$ reduction in bone mass; ${ }^{21}$ type 2 diabetics are less severely affected. Anorexia or poor diet, low body weight, associated amenorrhoea and hypercortisolism can cause rapid osteoporosis. $^{22}$ Bone loss also occurs in hypogonadal males, in hyperparathyroidism, after heparin treatment $^{23}$ and in alcoholism ${ }^{24}$ (it is now recognised that bone loss may occur with only moderate alcohol intake, at least in women, ${ }^{25}$ implying that patients should be encouraged to reduce intake if necessary).

The value of drug prophylaxis against bone loss in those at risk has been the subject of intensive research, and as yet firm conclusions are lacking. Calcium and vitamin $\mathrm{D}$ supplementation have been shown to ameliorate bone $\operatorname{loss}^{26}$ and bisphosphonates unarguably reduce bone loss and replenish bone once lost. ${ }^{5,27}$ Other drugs such as calcitriol ${ }^{28}$ and calcitonin ${ }^{29}$ prove beneficial in some circumstances. However, the only adverse event associated with bone loss is bone fracture, and the effect of prophylaxis on fracture prevalence has not been conclusively established. Nevertheless there is now a medical consensus on the need to treat in some circumstances.

The National Osteoporosis Society (NOS), in association with The British Society for Rheumatology, the Royal Society of Medicine and others, has published guidelines on the prevention and management of steroid-induced osteoporosis. ${ }^{30}$ Although this is only one of a plethora of published guidelines, it has the benefit of clarity, conciseness and a practical approach. It is possible that further studies will confirm our impressions that the risks of bone loss are low for patients with uveitis, but pending such studies the NOS guideline provides a useful safety protocol for the ophthalmologist.

Patients using $5 \mathrm{mg}$ of prednisolone or more per day for several months or more should be considered at risk of bone loss. This will exclude, for instance, those taking steroids for an average 8-10 weeks in the management of acute ocular toxoplasmosis. All such patients should be informed about bone loss and other complications. Adequate dietary calcium and vitamin $\mathrm{D}$ should be maintained (deficiency in a Western diet is unusual but guidelines are readily available). If there is any doubt about dietary intake or if the patient is relatively immobile, supplementary calcium and vitamin D3 should be taken. Alcohol intake should be limited to recommended norms. Smokers should be encouraged to stop. Walking for the equivalent of two miles or more per day should be encouraged if possible. Post-menopausal women already using HRT should be encouraged to continue if risks are acceptable. Patients should be screened for additional risk factors. If there are none, if the patient is under 65 and the dosage is under $15 \mathrm{mg} /$ day, no further action is necessary. If the steroid dosage is $>15 \mathrm{mg} /$ day, if the patient is over 65 , or if there are additional risk factors, the NOS guideline should be followed.

If treatment is considered necessary, the drug of choice for all patients is a bisphosphonate. The optimum form of treatment for steroid-induced bone loss is still subject to review, the two main choices being cyclical etidronate with calcium, or weekly alendronate. Post-menopausal women alternatively can use HRT, which will require the agreement and cooperation of the general practitioner. Patients requiring treatment also require assessment for additional risk factors. If any patient has suffered a fracture, we recommend referral to a physician with an expertise in the management of osteoporosis. We also recommend such referral if a patient is intolerant of bisphosphonate treatment (typically because of heartburn) or for any patient under 65 with osteoporosis $(\mathrm{T}<-2.5)$.

Systemic steroids remain the mainstay of treatment for most severe inflammatory diseases despite the increasing availability of immunosuppressives. However, immunosuppressives (most frequently cyclosporin) were used in over one quarter of our patients in order to lower steroid dosage. These drugs allow a reduction in steroid dose in most patients, often by $50 \%$ or more and thus bone loss may be ameliorated. However, it is known that cyclosporin itself causes high-turnover bone loss, possibly by reducing testosterone in combination with other 
effects. ${ }^{31-33}$ The combination of prednisolone and cyclosporin could theoretically increase bone loss, but in this series only one of 27 patients using cyclosporin was osteoporotic.

The frequency of male osteoporosis $(14 / 68,20.6 \%)$ in this study is striking, and all of these were $60 \mathrm{yrs}$ or below. In contrast only 6/61 women $(9.8 \%)$ were osteoporotic, and four of these were over $60 \mathrm{yrs}$. There is no significant difference between the treatment parameters of males and females in this study. The use of $\mathrm{T}<-2.5$ to define osteoporosis in men is not universally accepted as it is for women, because of the technicalities of the interpretation of bone density. ${ }^{34,35}$ Young men have the greatest risk of high-impact fracture, and osteoporosis is common in those with associated risk factors, ${ }^{36}$ especially hypogonadism. Men are also more susceptible to bone loss at equivalent doses of steroid, than are premenopausal women. ${ }^{6}$ They should be considered an at-risk group ${ }^{37,38}$ and it is reasonable to define both male and female osteoporosis using the same criteria.

In conclusion, steroid-induced osteoporosis is an important cause of morbidity. This study suggests that its prevalence is lower in patients with uveitis than in some other disease groups but has highlighted the risk to young men. Bone loss can be reduced by optimising lifestyle and diet, by the identification of pre-existing risk factors and by the use of appropriate prophylaxis and treatment.

\section{Acknowledgements}

We wish to acknowledge the support of the Iris Fund for Mr Stanford.

The authors have no financial or proprietary interest in any device or medication reported in this article.

\section{References}

1 Hodgkins P, Hull RG, Evans AR, Jeffrey MN. Osteoporosis: a survey of consultant ophthalmologists. $\mathrm{Br}$ J Ophthalmol 1997; 81: 260.

2 Walsh LJ, Wong CA, Pringle M, Tattersfield AE. Use of oral corticosteroids in the community and the prevention of secondary osteoporosis: a cross sectional study. $\mathrm{Br} \mathrm{Med}$ J 1996; 313: 344-346.

3 Stanbury R, Graham EM. Systemic corticosteroid therapy - side effects and their management. $\mathrm{Br} \mathrm{J}$ Ophthalmol 1998; 82: 704-708.

4 Jabs DA, Rosenbaum JT, Foster CS, Holland GN, Jaffe GJ, Louie JS et al. Perspective: guidelines for the use of immunosuppressive drugs in patients with ocular inflammatory disorders: recommendations of an expert panel. Am J Ophthalmol 2000; 130: 492-513.

5 Mulder H, Struys SA. Intermittent cyclical etidronate in the prevention of corticosteroid-induced bone loss. $\mathrm{Br} \mathrm{J}$ Rheumatol 1994; 33: 439-447.
6 Lukert BP, Raisz LG. Glucocorticoid induced osteoporosis; pathogenesis and management. Ann Intern Med 1990; 112: 353-3564.

7 Baillie SP, Davison CE, Johnson FJ, Francis RM. Pathogenesis of vertebral crush fractures in men. Age Ageing 1992; 21: 139-141.

8 Reid DM. Corticosteroid osteoporosis. In: Francis RM (ed). Osteoporosis: Pathogenesis and Management. Kluwer: Lancaster, 1990, pp 103-144.

9 Cooper C, Coupland C, Mitchell M. Rheumatoid arthritis, corticosteroid therapy and hip fracture. Ann Rheum Dis 1995; 54: 49-52.

10 Lees B, Banks LM, Stevenson JC. Bone mass measurements. In: Stevenson JC, Lindsay R (eds) Osteoporosis. Chapman \& Hall: London, 1998, pp 137-155.

11 Hahn TJ, Boisseau VC, Avioli LV. Effect of chronic corticosteroid administration on diaphyseal and metaphyseal bone mass. J Clin Endocrinol Metab 1974; 39: 274-282.

12 Mueller MN. Effects of corticosteroids on bone mineral in rheumatoid arthritis and asthma. Am J Roentgenol 1976; 126: 1300.

13 Reid DM, Nicoll JJ, Smith MA et al. Corticosteroids and bone mass in asthma: comparisons with rheumatoid arthritis and polymyalgia rheumatica. $\mathrm{Br}$ Med J 1986; 293 : 1463-1464.

14 Baschieri L, Antonelli A, Nardi S et al. Intravenous immunoglobulin versus corticosteroid in treatment of Graves' ophthalmopathy. Thyroid 1997; 7: 579-585.

15 Tamesis RR, Rodriguez A, Christen WG, Akova YA, Messmer E, Foster CS. Systemic drug toxicity trends in immunosuppressive therapy of immune and inflammatory ocular disease. Ophthalmology 1996; 103 768-775.

16 Michel BA, Bloch DA, Fries JF. Predictors of fractures in early rheumatoid arthritis. J Rheumatol 1991; 18: 804-808.

17 Adinoff AD, Hollister JR. Steroid-induced fractures and bone loss in patients with asthma. N Engl J Med 1983; 309: 265-268.

18 Aitken JM, Hart DM, Anderson JB et al. Osteoporosis after oophorectomy for malignant disease in premenopausal women. Br Med J 1973; 2: 325-328.

19 Greenstein AJ, Janowitz HD, Sachar DB. The extraintestinal complications of Crohn's disease and ulcerative colitis: a study of 700 patients. Medicine 1976; 55: 401-412.

20 Hahn TJ, Boisseau VC, Avioli LV. Effect of chronic corticosteroid administration on diaphyseal and metaphyseal bone mass. Clin Endocrinol Metab 1974; 39 274-282.

21 Selby PL. Osteopenia and diabetes. Diabetic Med 1988; 94: 257-264.

22 Rigotti NA, Neer RM, Skates SJ, Herzog DB, Nussbaum SR. The clinical course of osteoporosis in anorexia nervosa. A longitudinal study of cortical bone mass. JAMA 1991; 265: 1133-1138.

23 Griffith GC, Nicholas G, Asher JD, Flanagan B. Heparin osteoporosis. JAMA 1965; 193: 91-94.

24 Saville PD. Changes in bone mass with age and alcoholism. J Bone Joint Surg 1965; 47B: 492-499.

25 Nordin BEC, Polley KJ. Metabolic consequences of the menopause. Calcif Tissue Int 1987; 41(suppl): 1-59.

26 Buckley LM, Leib ES, Cartularo KS, Vacek PM, Cooper $\mathrm{SM}$. Calcium and vitamin D3 supplementation prevents bone loss in the spine secondary to low-dose 
corticosteroids in patients with rheumatoid arthritis. Ann Intern Med 1996; 125: 961-968.

27 Struys A, Snelder AA, Mulder H. Cyclical etidronate reverses bone loss of the spine and proximal femur in patients with established corticosteroid-induced osteoporosis. Am J Med 1995; 99: 235-242.

28 Sambrook P, Birmingham J, Kelly P et al. Prevention of corticosteroid osteoporosis. A comparison of calcium, calcitriol, and calcitonin. N Engl J Med 1993; 328: 17471752.

29 Cranney A, Welch V, Adachi JD et al. Calcitonin for the treatment and prevention of corticosteroid-induced osteoporosis. Cochrane Database Syst Rev 2000; 2: CD001983.

30 Anon. Guidance on the Prevention and Management of Corticosteroid Induced Osteoporosis. National Osteoporosis Society: Bath, 1998.

31 Thiebaud D, Krieg MA, Gillard-Berguer D, Jacquet AF, Goy JJ, Burckhardt P. Cyclosporine induces high bone turnover and may contribute to bone loss after heart transplantation. Eur J Clin Invest 1996; 26: 549-555.

32 Bowman AR, Sass DA, Dissanayake IR et al. The role of testosterone in cyclosporine-induced osteopenia. J Bone Miner Res 1997; 12: 607-615.

33 Stekelenburg J, Klein BY, Ben-Bassat H, Rojansky N Opposing effects of cyclosporin A and tryphostin AG1478 indicate a role for Src protein in the cellular control of mineralisation. J Cell Biochem 1998; 71: 116-126.

34 Anderson FH. Osteoporosis in men. Int J Clin Pract 1998; 52: $176-180$.

35 Melton LJ, Khosla S, Achenbach SJ, O'Connor MK, O'Fallon WM, Riggs BL. Effects of body size and skeletal site on the estimated prevalence of osteoporosis in women and men. Osteoporos Int 2000; 11: 977-983.

36 Kelepouris N, Harper KD, Gannon F, Kaplan FS, Haddad JG. Severe osteoporosis in men. Ann Intern Med 1995; 123: 452-460.

37 Legrand E, Chappard D, Pascaretti C, Duquenne M, Rondeau C, Simon Y et al. Bone mineral density and vertebral fractures in men. Osteoporos Int 1999; 10: 265270.

38 Melton LJ, Atkinson EJ, O'Connor MK, O'Fallon WM, Riggs BL. Bone density and fracture risk in men. J Bone Miner Res 1998; 13: 1915-1923. 